\title{
A Course on Endovascular Training for Resuscitative Endovascular Balloon Occlusion of the Aorta (ET- REBOA): A Pilot Study for Residents and Specialists
}

\section{Sung Wook Chang}

Dankook University Hospital

\section{Seok Won Lee}

Dankook University Hospital

\section{Han Cheol Jo}

Dankook University Hospital

Dong Hun Kim

Dankook University Hospital

Ye Rim Chang ( $\nabla$ yerimchang@gmail.com )

Dankook University Hospital https://orcid.org/0000-0002-2177-2304

\section{Research article}

Keywords: Resuscitation, Aorta, Balloon Occlusion, Education

Posted Date: October 17th, 2019

DOl: https://doi.org/10.21203/rs.2.16178/v1

License: (9) (1) This work is licensed under a Creative Commons Attribution 4.0 International License. Read Full License

Version of Record: A version of this preprint was published at Annals of Surgical Treatment and Research on January 1st, 2020. See the published version at https://doi.org/10.4174/astr.2020.99.6.362. 


\section{Abstract}

Background: Resuscitative endovascular balloon occlusion of the aorta (REBOA) has emerged as a salvage technique changing the paradigm in the management of non-compressible torso hemorrhage. However, training for the REBOA procedure is rarely performed. The endovascular training for REBOA (ET-REBOA) course was conducted to develop the endovascular skills of participants.

Methods: Sixteen residents and 12 specialists participated in this educational course. All participants were provided with pre-course learning materials that consisted of a lecture on the introduction of REBOA and a demonstration video clip a week before the course. The ET-REBOA course consisted of two sections: an ultrasound-guided sheath insertion on the puncture model, and a balloon manipulation on the vascular circuit model. A 13-item procedure checklist and the time required to perform the procedure were examined. Pre/post selfreported confidence score and course satisfaction questionnaire was obtained.

Results: Twenty-eight participants performed the 56 REBOA procedures. Seven of 16 residents failed their first attempt. On the first attempt, the median total time for REBOA from ultrasound-guided vascular access to balloon inflation was $1139 \pm 250 \mathrm{~s}$ in the resident group and $828 \pm 280 \mathrm{~s}$ in the specialist group. The median shortened time for completion was $273 \mathrm{~s}$ in the resident group and $290 \mathrm{~s}$ in the specialist group. A significant decrease in procedure task time was observed between first and second attempt in the resident group $(p=0.016)$, specialist group ( $p=0.004)$, and in total amongst all participants $(p<0.001)$.

Conclusion: The ET-REBOA course significantly decreased the time taken to perform the REBOA procedure with high satisfaction of the participants. The course could be an effective curriculum for the development of endovascular skills for performing REBOA.

\section{Background}

Non-compressible torso hemorrhage (NCTH), which is caused by abdominopelvic and thoracic injuries, is still the primary cause of preventable death in trauma [1]. To improve the survival of patients with NCTH, early and effective resuscitation with hemorrhage control is mandatory. In an effort to decrease bleeding below the clamped site while maintaining cerebral and coronary perfusion, resuscitative thoracotomy (RT) [2] followed by aortic cross clamp (ACC) can be performed in moribund patients as a damage control surgery. However, RT remains associated with high morbidity and mortality $[2,3]$, which acts as a burden against performing the procedure.

Recently, REBOA has been gaining acceptance as an alternative to RT followed by ACC in the management of select patients with NCTH [4-7]. The paradigm is shifting with respect to the management of hemorrhagic shock from abdominopelvic injury since REBOA provides the physiologic benefit of temporary aortic occlusion without the burden of thoracotomy [8]. However, the REBOA procedure remains limited and is regarded as difficult because of the absence of knowledge, experience, and proper training amongst physicians. The purpose of this study was to introduce the endovascular training for REBOA (ET-REBOA) course and to evaluate its effectiveness.

\section{Methods}

Sixteen residents and 12 specialists from Dankook University Hospital with no prior experience in performing the REBOA procedure participated in this educational course. All specialists were board-certified and included: six 
emergency physicians, four general surgeons, one cardiothoracic surgeon, and one neurosurgeon who took calls in the Trauma Resuscitation Unit at the level I trauma center in Dankook University Hospital (Fig. 1). The course was conducted by four full-time trauma faculty members (one cardiothoracic surgeon and three general surgeons) from Dankook University Hospital who had experience with the REBOA procedure as well as the educational model. Each trainee was matched to two instructors at a time.

All participants were provided with pre-course learning materials one week prior to the course. These lecture notes provided an introduction to the aortic zone, role, indication and sequences of REBOA. The demonstration videos (Fig. 2) included instructions on how to perform the preparations (sheath, wire, and balloon catheter) and procedures (ultrasound-guided vascular access, balloon insertion, and balloon inflation in accordance to the target level). On the day of training, 60 minutes of lecture plus discussion was provided.

The course consisted of two sections: 1) ultrasound-guided sheath insertion and 2) balloon manipulation. Ultrasound-guided sheath insertion was performed on the lower torso model Blue Phantom ${ }^{\mathrm{TM}}$ (Femoral Vascular Access Lower Torso Ultrasound Model, CAE Healthcare, Texas, USA) using 7 Fr Radiofocus ${ }^{\circledR}$ Introducer II (Terumo, Tokyo, Japan). This model is a manikin with femoral vascular access replacement tissue, which allows for realistic ultrasound imaging to guide needle and catheter insertions into the pulsated femoral artery distinguished from vein. The balloon was inserted and inflated on the vascular circuit model EVE ${ }^{T M}$ (EndoVascular Evaluator, BR Biomedicals Pvt. Ltd., New Delhi, India) using 7 Fr RESCUE Balloon ${ }^{T M}$ (Tokai Medical Products, Aichi, Japan). This model is made of special silicone that recreates the elasticity and friction of human vasculature, simulating the sensation and behavior of catheter manipulation during an endovascular procedure. Artery pulsation can be simulated using a pulsed flow pump, the pressure of which can be changed by aortic occlusion. It also provides compatibility with a wide range of X-ray imaging techniques.

Each section was repeated twice, and the time taken to complete each procedure was recorded to evaluate improvements in the skill of the participants. Participants performed both zone I and III REBOA alternately using two case scenarios: 1) a moribund patient with a massive hemoperitoneum confirmed by Focused Assessment with Sonography for Trauma (zone I) and 2) an unstable pelvic bone fracture by pelvic X-ray (zone III). Portable Xray (Fig. 3) was taken to check the position of the guidewire and balloon during the course.

The procedure checklist contained a total of 13 items (Table 1). Participants received a "fail" if they: 1) did not successfully access a femoral artery using the ultrasound-guided technique, 2) inflated the REBOA balloon during preparation, 3) did not change from the soft guidewire to the stiff wire before balloon inflation, or 4) inflated the balloon before checking the balloon position. Residents who failed their first attempt were given additional opportunities to acquire the correct skills without a time limit. Instructors gave tips and feedback to the participants immediately after the first attempt according to the checklist.

Participants rated their confidence in performing REBOA immediately before and after the course on a scale from 1 (strongly disagree) to 10 (strongly agree). The post-assessment contained the same questions as the preassessment. After completing the course, participants also completed an 11-item course satisfaction questionnaire, which also employed a 10-point scale.

For the course analysis, continuous variables were compared using paired $t$ tests, and $P$-values $<0.05$ were considered statistically significant. All statistical analyses were performed using PASW Statistics 19 (IBM Corp., Somers, NY, USA). This study was approved by the Institutional Review

Page $3 / 15$ 


\section{Results}

A total of 56 REBOA procedures were performed in the ET-REBOA course by 28 participants. No one in the specialist group failed the procedure on their first attempt. However, seven of the 16 residents (five junior residents and two senior residents) failed their first attempt. According to the procedure checklists there were 10 reasons for failure: no sheath priming $(n=1)$, no guidewire priming $(n=1)$, no balloon priming $(n=2)$, balloon test before insertion $(n=1)$, balloon inflation before insertion of a stiff wire $(n=2)$, and balloon inflation before checking the balloon position $(n=3)$.

On the first attempt, the median time from ultrasound-guided vascular access to balloon inflation was $1139 \pm 250$ s (range: $513-1329 \mathrm{~s}$ ) in the resident group and $828 \pm 280 \mathrm{~s}$ (range: 478-1384 s) in the specialist group. For residents and specialists who performed the REBOA procedures successfully in both attempts, the time for completion of the procedure was shorter at the second attempt compared to that at the first attempt, with the median shortened time for completion being $273 \mathrm{~s}$ in the resident group and $290 \mathrm{~s}$ in the specialist group (Fig. 4). A significant decrease in procedure task time was observed between first and second attempt in the resident group $(p=0.016)$, specialist group $(p=0.004)$, and in total amongst all participants $(p<0.001)$ (Table 2$)$. With regards to each procedure, time for balloon insertion decreased more in the resident group (198 s), while time for ultrasoundguided vascular access decreased more in the specialist group (116 s). The residents who failed their first attempt all successfully completed procedure during their second attempt, with a median time of $852 \mathrm{~s}$ (Fig. 4). Line plots of the time taken to complete procedures for each participant show a dramatic decrease between the first and second attempts, except for one participant from the resident group (Fig. 5).

Previous experience with ultrasound-guided vascular access or femoral vessel catheterization did not make a difference in the time taken to complete the procedure (Table 3). The length of time required for balloon placement in zones I and III also was not different among participants.

Self-reported confidence scores increased most for the item "I know how to inflate/deflate a balloon correctly," which had the lowest score before the course. The item "I know which vessel to puncture" ranked highest in the post-course assessment (Table 4). On the course satisfaction questionnaire, "I would recommend the ET-REBOA course to my colleagues" was the item with the highest score while "I feel ready to do REBOA in the clinical practice" was the item with the lowest (Table 5).

\section{Discussion}

The time and place where REBOA has the greatest potential to improve survival after trauma are at patient presentation to the resuscitation area or shortly thereafter [9]. Although it is essential to attain proficiency before performing the procedure at this critical juncture, most physicians have limited exposure to endovascular techniques. There are limited reports on endovascular training $[8,9]$, even though REBOA has been increasingly used worldwide over the past decades [5, 10-13].

Several educational courses teach the REBOA procedure: examples include the Endovascular Skills for Trauma and Resuscitative Surgery (ESTARS) course [8] and the EndoVascular resuscitation, bleeding and Trauma Management (EVTM) hands-on workshop. The ESTARS course is mainly composed of didactics focused on 
vascular injury including surgical and endovascular techniques, and the EVTM hands-on workshop is concentrated on stormy discussion and the practice of EVTM using a multidisciplinary team approach. The ETREBOA course places emphasis on understanding and performing the REBOA procedure. Therefore, the ET-REBOA pilot course was rated highly satisfactory (score 9.57) and was highly recommended (score 9.71) by the participants who wanted to learn the REBOA procedure.

There are several differences between this course and other courses. First, the ET-REBOA course adopted a modified form of a flipped learning. Flipped learning is a pedagogical approach where students are introduced to the learning material before class, which positively impacts self-directed learning readiness and engages students more in the content [14]. Pre-course learning materials in the form of lecture notes and videos provided one week prior to the course seemed to be satisfactory and helpful, with mean scores of 9.04 and 9.11, respectively, according to the questionnaire. Second, the devices used in the course allowed for realistic ultrasound imaging and provided the sensation of catheter manipulation during an endovascular procedure. A 7 Fr RESCUE Balloon ${ }^{\mathrm{TM}}$ was used to teach basic manipulation of the balloon as well as the difference in sensation between total and partial occlusion. Third, checklists were used to emphasize and imprint steps essential to the success of the REBOA procedure.

In this study, there was a significant decrease in procedure task time between the first and second attempts among participants. Novice trainees also significantly improved their performance after the course. This may suggest that this procedure can be learned and performed regardless of years of training or practice.

Interestingly, previous experience with ultrasound-guided vascular access or other endovascular procedures (vascular access via the Seldinger approach into a femoral artery/vein) did not affect performance measures. This may present the question of whether the model allows for a realistic experience with the REBOA procedure. Although these devices are optimized for endovascular training, gaps between in vivo and ex vivo experience may still exist. The effect of this pilot course will be evaluated at a later date by comparing the following clinical outcomes of trauma patients who were managed with REBOA before and after their physicians took this course: procedure-related complications, duration of procedure, and patient outcome.

After this pilot study, there were several updates in the course targeting the traumatologists practicing at trauma center in South Korea. The course was modified to comprise lectures, discussion, three hands-on sessions, $5 \mathrm{Fr}$ sheath insertion, sheath upsizing (5 Fr to $7 \mathrm{Fr}$ sheath), and balloon manipulation. Three instructors were assigned to each hands-on session, and participants assembled into teams of three to four, where they took turns playing the role of operator, assistant, and checklist recorder.

\section{Conclusions}

In conclusion, the ET-REBOA course significantly decreased the time taken to perform the REBOA procedure with high satisfaction of the participants. The course could be an effective addition to the curriculum for the development of endovascular skills for performing REBOA.

\section{List Of Abbreviations}

ACC, Aortic cross clamp; ESTARS, Endovascular Skills for Trauma and Resuscitative Surgery; ET-REBOA, endovascular training for resuscitative endovascular balloon occlusion of the aorta; EVTM, EndoVascular 
resuscitation, bleeding and Trauma Management; NCTH, Non-compressible torso hemorrhage; REBOA, Resuscitative endovascular balloon occlusion of the aorta; RT, Resuscitative thoracotomy

\section{Declarations}

\section{Ethics approval and consent to participate}

: This study complied with the Declaration of Helsinki and was approved by the Institutional Review Board of the Dankook University Hospital (IRB No. 201910001). Written informed consent was obtained from all patients.

\section{Consent for publication}

: Not applicable

\section{Availability of data and material}

: All data generated or analyzed during this study are included in this published article. The data are available from the corresponding author upon reasonable request.

\section{Competing interests}

: The authors declare no competing interests.

\section{Funding}

: None

\section{Authors' contributions}

SWC designed the course; SWC and DHK made pre-course learning material; SWC, SWL, HCJ, and YRC were the instructors of the course; SWC and YRC analyzed data and wrote the manuscript; All authors read and approved the final manuscript.

\section{Acknowledgements}

The authors appreciate the support received from the Chi Young Lee, the President \& C. E.O of Intervention Medical Co., Ltd for providing 7 Fr Radiofocus ${ }^{\circledR}$ Introducer II and 7 Fr RESCUE Balloon ${ }^{\text {TM }}$.

\section{References}

1. Andres J, Scott J, Giannoudis P V. Resuscitative endovascular balloon occlusion of the aorta (REBOA): What have we learned? Injury. 2016;47:2603-5. 
2. Belenkiy SM, Batchinsky Al, Rasmussen TE, Cancio LC. Resuscitative endovascular balloon occlusion of the aorta for hemorrhage control: Past, present, and future. J Trauma Acute Care Surg. 2015;79:S236-42.

3. Seamon MJ, Haut ER, Van Arendonk K, Barbosa RR, Chiu WC, Dente CJ, et al. An evidence-based approach to patient selection for emergency department thoracotomy. J Trauma Acute Care Surg. 2015;79:159-73.

4. Kim DH, Chang SW, Matsumoto J. The utilization of resuscitative endovascular balloon occlusion of the aorta: preparation, technique, and the implementation of a novel approach to stabilizing hemorrhage. $J$ Thorac Dis. 2018;10:5550-9.

5. Sadeghi M, Nilsson KF, Larzon T, Pirouzram A, Toivola A, Skoog P, et al. The use of aortic balloon occlusion in traumatic shock: first report from the ABO trauma registry. Eur J Trauma Emerg Surg. 2018;44:491-501.

6. Saito N, Matsumoto H, Yagi T, Hara Y, Hayashida K, Motomura T, et al. Evaluation of the safety and feasibility of resuscitative endovascular balloon occlusion of the aorta. J Trauma Acute Care Surg. 2015;78:897-904.

7. Moore LJ, Brenner M, Kozar RA, Pasley J, Wade CE, Baraniuk MS, et al. Implementation of resuscitative endovascular balloon occlusion of the aorta as an alternative to resuscitative thoracotomy for noncompressible truncal hemorrhage. J Trauma Acute Care Surg. 2015;79:523-32.

8. Villamaria CY, Eliason JL, Napolitano LM, Stansfield RB, Spencer JR, Rasmussen TE. Endovascular Skills for Trauma and Resuscitative Surgery (ESTARS) course. J Trauma Acute Care Surg. 2014;76:929-36.

9. Brenner M, Hoehn M, Pasley J, Dubose J, Stein D, Scalea T. Basic endovascular skills for trauma course. J Trauma Acute Care Surg. 2014;77:286-91.

10. Qasim Z, Brenner M, Menaker J, Scalea T. Resuscitative endovascular balloon occlusion of the aorta. Resuscitation. 2015;96:275-9.

11. Gamberini E, Coccolini F, Tamagnini B, Martino C, Albarello V, Benni M, et al. Resuscitative Endovascular Balloon Occlusion of the Aorta in trauma: a systematic review of the literature. World J Emerg Surg. 2017;12:42.

12. Morrison JJ, Galgon RE, Jansen JO, Cannon JW, Rasmussen TE, Eliason JL. A systematic review of the use of resuscitative endovascular balloon occlusion of the aorta in the management of hemorrhagic shock. $J$ Trauma Acute Care Surg. 2016;80:324-34.

13. King DR. Initial Care of the Severely Injured Patient. N Engl J Med. 2019;380:763-70.

14. Ihm J, Choi H, Roh S. Flipped-learning course design and evaluation through student self-assessment in a predental science class. Korean J Med Educ. 2017;29:93-100.

\section{Tables}

Table 1. Procedure checklist 


\begin{tabular}{|c|c|c|c|c|}
\hline & Items & $\begin{array}{l}\text { Not } \\
\text { done }\end{array}$ & Incorrect & Correct \\
\hline \multirow{4}{*}{$\begin{array}{l}\text { Sheath } \\
\text { insertion }\end{array}$} & Sheath priming & & & $\mathrm{V}$ \\
\hline & Ultrasound-guided puncture & & & V \\
\hline & Sheath guidewire insertion & & & V \\
\hline & Sheath insertion* & & & V \\
\hline \multirow{9}{*}{$\begin{array}{l}\text { Balloon } \\
\text { insertion }\end{array}$} & Guidewire priming & & & $\mathbf{V}$ \\
\hline & Balloon priming & & & V \\
\hline & Balloon test ${ }^{\dagger}$ & V & & \\
\hline & Guidewire position check & & & V \\
\hline & $\begin{array}{l}\text { Balloon position measurement using body } \\
\text { landmarks }\end{array}$ & & & $\mathbf{v}$ \\
\hline & Balloon insertion & & & V \\
\hline & Stiff wire insertion before inflation* & & & V \\
\hline & Balloon position check before inflation* & & & $\mathbf{V}$ \\
\hline & Final balloon position & & & V \\
\hline
\end{tabular}

"Participants received a "fail" grade if they did not complete the item.

†Participants received a "fail" grade if they inflated the REBOA balloon during preparation.

Table 2. Time to complete the procedure among participants 


\begin{tabular}{|c|c|c|c|c|}
\hline \multirow[t]{2}{*}{ Participants } & \multirow[t]{2}{*}{ Procedure } & \multicolumn{2}{|c|}{$\begin{array}{l}\text { Time (mean, } \\
\text { seconds) }\end{array}$} & \multirow[t]{2}{*}{$p$-value } \\
\hline & & $\begin{array}{c}1^{\text {st }} \\
\text { attempt }\end{array}$ & $\begin{array}{c}2^{\text {nd }} \\
\text { attempt }\end{array}$ & \\
\hline \multirow[t]{3}{*}{$\begin{array}{l}\text { Residents who successfully completed the } \\
\text { procedure }(\mathrm{n}=9)\end{array}$} & $\begin{array}{l}\text { Vascular } \\
\text { access }\end{array}$ & 443.0 & 287.4 & 0.124 \\
\hline & $\begin{array}{l}\text { Balloon } \\
\text { insertion }\end{array}$ & 579.2 & 423.9 & 0.048 \\
\hline & Total & 1022.2 & 711.3 & 0.016 \\
\hline \multirow{3}{*}{$\begin{array}{c}\text { Specialists } \\
(\mathrm{n}=12)\end{array}$} & $\begin{array}{l}\text { Vascular } \\
\text { access }\end{array}$ & 438.2 & 225.2 & 0.011 \\
\hline & $\begin{array}{l}\text { Balloon } \\
\text { insertion }\end{array}$ & 433.1 & 340.5 & 0.013 \\
\hline & Total & 871.3 & 565.7 & 0.004 \\
\hline \multirow[t]{3}{*}{$\begin{array}{l}\text { All participants who successfully completed the } \\
\text { procedure }(\mathrm{n}=21)\end{array}$} & $\begin{array}{l}\text { Vascular } \\
\text { access }\end{array}$ & 440.2 & 251.9 & 0.002 \\
\hline & $\begin{array}{l}\text { Balloon } \\
\text { insertion }\end{array}$ & 495.7 & 376.2 & 0.005 \\
\hline & Total & 935.9 & 628.1 & $<0.001$ \\
\hline
\end{tabular}

Table 3. Time to complete the procedure according to previous experience 


\begin{tabular}{|c|c|c|c|c|c|c|c|c|c|}
\hline \multicolumn{2}{|c|}{ Participants } & \multicolumn{4}{|c|}{ First attempt (mean, seconds) ${ }^{*}$} & \multicolumn{4}{|c|}{ Second attempt (mean, seconds) } \\
\hline & & $\begin{array}{l}\text { Vascular } \\
\text { access }\end{array}$ & $\begin{array}{l}\text { Balloon } \\
\text { insertion }\end{array}$ & Total & $p$-value & $\begin{array}{c}\text { Vascular } \\
\text { access }\end{array}$ & $\begin{array}{l}\text { Balloon } \\
\text { insertion }\end{array}$ & Total & $p$-value \\
\hline $\begin{array}{c}\text { I have seen } \\
\text { REBOA } \\
\text { before }\end{array}$ & $\begin{array}{l}\text { Yes } \\
(\mathrm{n} \\
= \\
23)\end{array}$ & 411.0 & 471.2 & 882.2 & 0.084 & 265.6 & 428.9 & 694.5 & 0.861 \\
\hline & $\begin{array}{l}\text { No } \\
\text { (n } \\
= \\
5)\end{array}$ & 564.5 & 600.0 & 1164.5 & & 394.2 & 336.6 & 730.8 & \\
\hline $\begin{array}{l}\text { I have prior } \\
\text { experience } \\
\text { with } \\
\text { ultrasound- } \\
\text { guided }\end{array}$ & $\begin{array}{l}\text { Yes } \\
(\mathrm{n} \\
= \\
18)\end{array}$ & 468.1 & 468.8 & 936.9 & 0.984 & 259.6 & 400.8 & 6600.3 & 0.314 \\
\hline $\begin{array}{l}\text { vascular } \\
\text { access }\end{array}$ & $\begin{array}{l}\text { No } \\
(\mathrm{n} \\
= \\
10)\end{array}$ & 384.6 & 549.6 & 934.1 & & 340.8 & 433.4 & 774.2 & \\
\hline $\begin{array}{l}\text { I have prior } \\
\text { experience } \\
\text { with other } \\
\text { endovascular } \\
\text { procedures }\end{array}$ & $\begin{array}{c}\text { Yes } \\
(\mathrm{n} \\
= \\
23)\end{array}$ & 418.6 & 487.3 & 905.9 & 0.501 & 295.6 & 436.6 & 732.1 & 0.070 \\
\hline & $\begin{array}{l}\text { No } \\
(\mathrm{n} \\
= \\
5)\end{array}$ & 509.6 & 522.6 & 1032.2 & & 256.4 & 301.4 & 557.8 & \\
\hline
\end{tabular}

*Failed residents were excluded from this analysis.

†Vascular access via Seldinger approach into femoral artery/vein

Table 4. Self-reported confidence score (10-point scale) 


\begin{tabular}{lllc}
\hline Items & $\begin{array}{c}\text { Pre-course } \\
\text { (mean, SD) }\end{array}$ & $\begin{array}{l}\text { Post-course } \\
\text { (mean, SD) }\end{array}$ & Difference \\
\hline I know how to perform ultrasound-guided vascular access. & $5.25(2.19)$ & $8.07(2.19)$ & 2.82 \\
I know which vessel to puncture. & $6.82(2.97)$ & $9.32(1.19)$ & 2.50 \\
I know how to insert a vascular sheath. & $6.36(2.37)$ & $8.64(1.87)$ & 2.29 \\
I know how to insert a guide wire. & $6.50(2.30)$ & $9.04(1.62)$ & 2.54 \\
I know when and how to insert a stiff guide wire. & $4.79(3.14)$ & $9.11(1.45)$ & 4.32 \\
I know how to position a balloon correctly. & $4.64(3.11)$ & $8.68(1.66)$ & 4.04 \\
I know how to inflate/deflate a balloon correctly. & $4.21(3.04)$ & $8.68(1.70)$ & 4.46 \\
\hline
\end{tabular}

$\mathrm{SD}$, standard deviation

Table 5. Post-course questionnaire (10-point scale)

\begin{tabular}{lcc}
\hline Items & Mean score & Standard deviation \\
\hline The pre-learning method was satisfactory. & 9.04 & 1.48 \\
Pre-course learning material was helpful. & 9.11 & 1.50 \\
The equipment used in the course was suitable for learning. & 8.96 & 1.71 \\
The course offered sufficient time to learn. & 9.29 & 1.15 \\
The level of difficulty of the course was appropriate for me. & 9.14 & 1.43 \\
I gained new knowledge. & 9.68 & 0.72 \\
I learned a new technique. & 9.64 & 0.78 \\
I feel ready to perform REBOA in clinical practice. & 7.93 & 2.36 \\
The course is worthwhile for trauma management. & 9.75 & 0.65 \\
I am pleased that I took the course. & 9.57 & 0.79 \\
I would recommend the ET-REBOA course to my colleagues. & 9.71 & 0.71
\end{tabular}

\section{Figures}



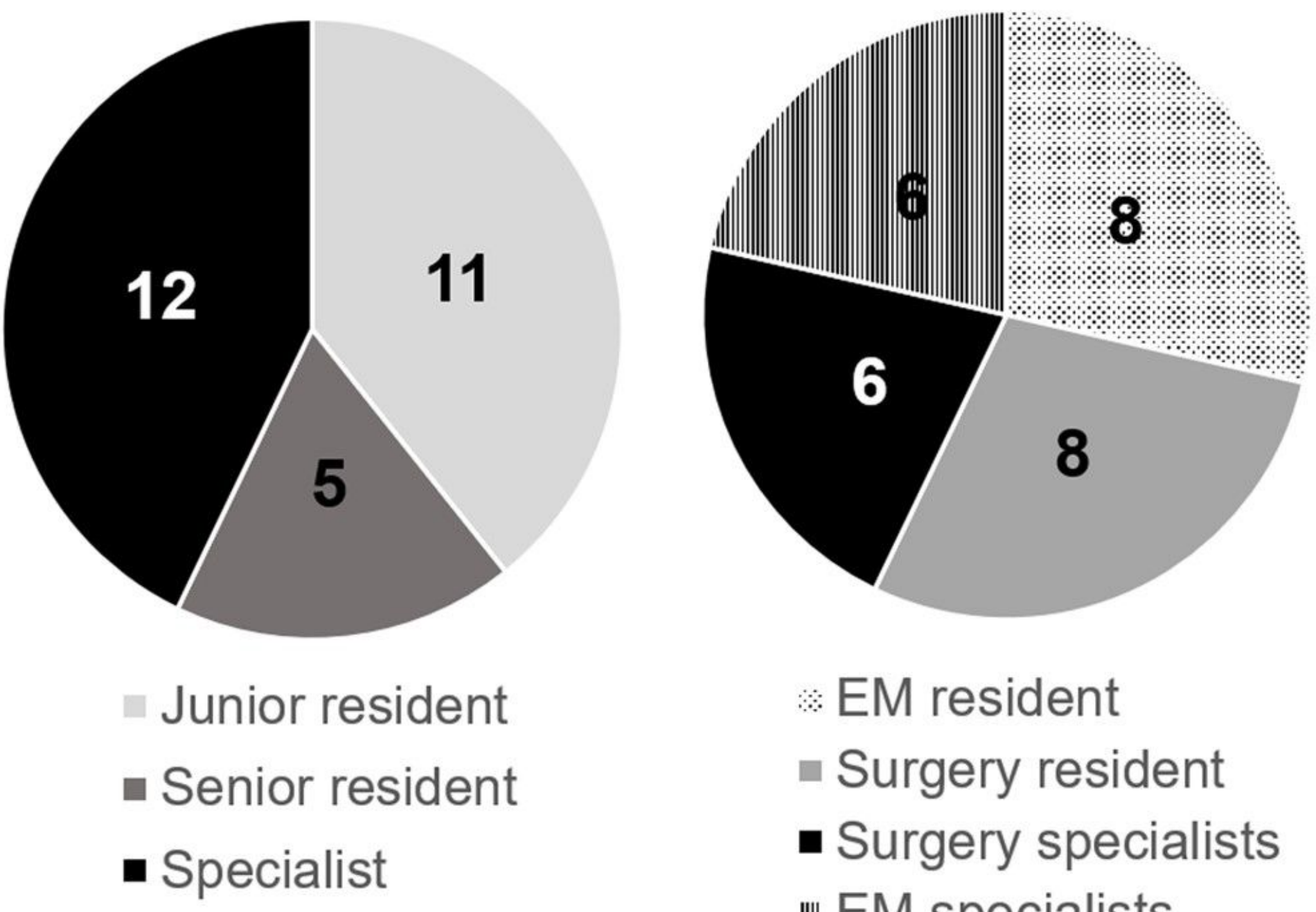

$\%$ EM resident

- Surgery resident - Surgery specialists III EM specialists

Figure 1

Participants Eleven junior residents, five senior residents, and 12 specialists participated in the course. Surgeons and emergency physicians comprised $50 \%$, respectively. 

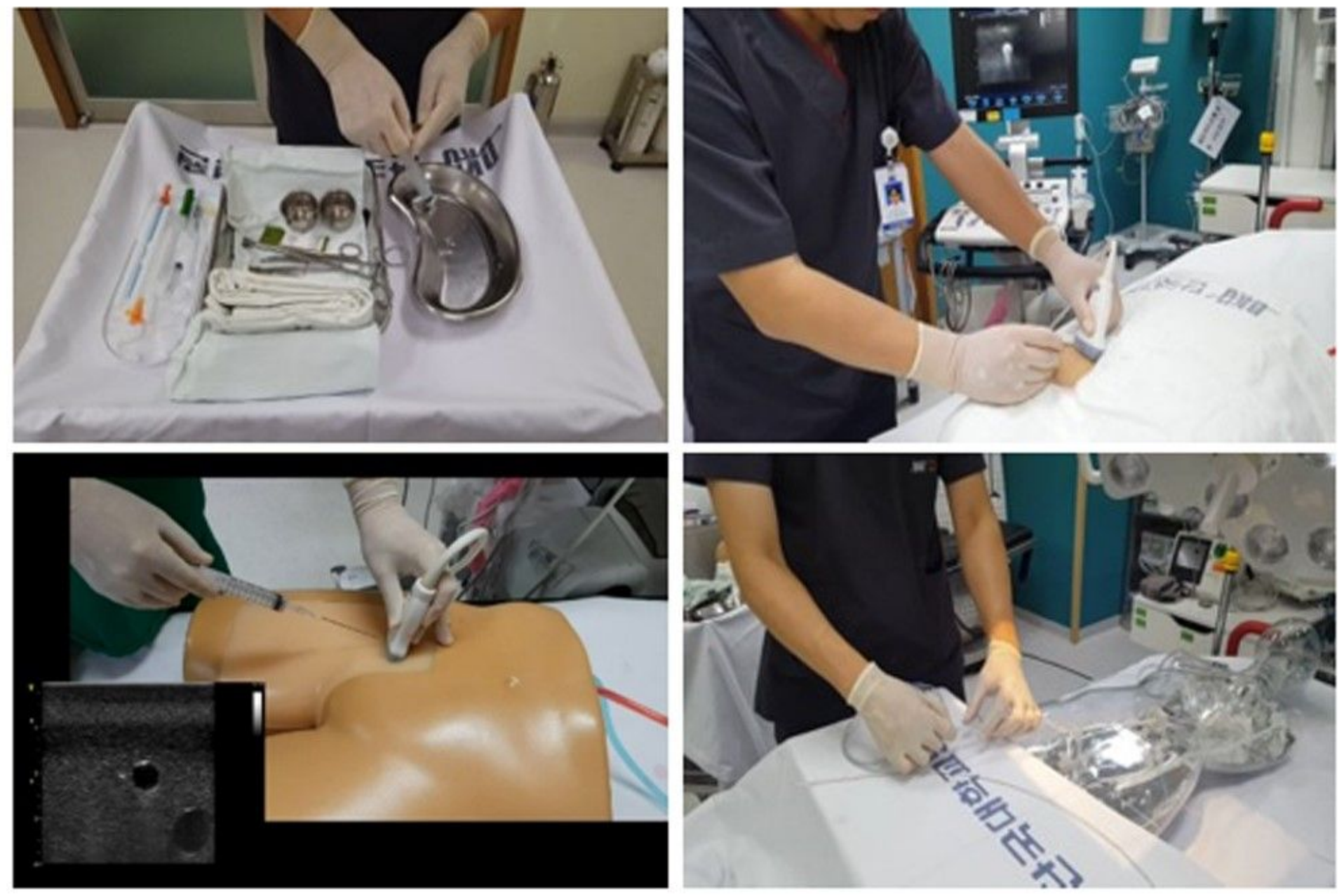

\section{Figure 2}

Pre-course learning materials Demonstration videos showing still frames of how to do the preparations (left upper), ultrasound-guided vascular access (right upper and left lower), and balloon insertion (right lower).
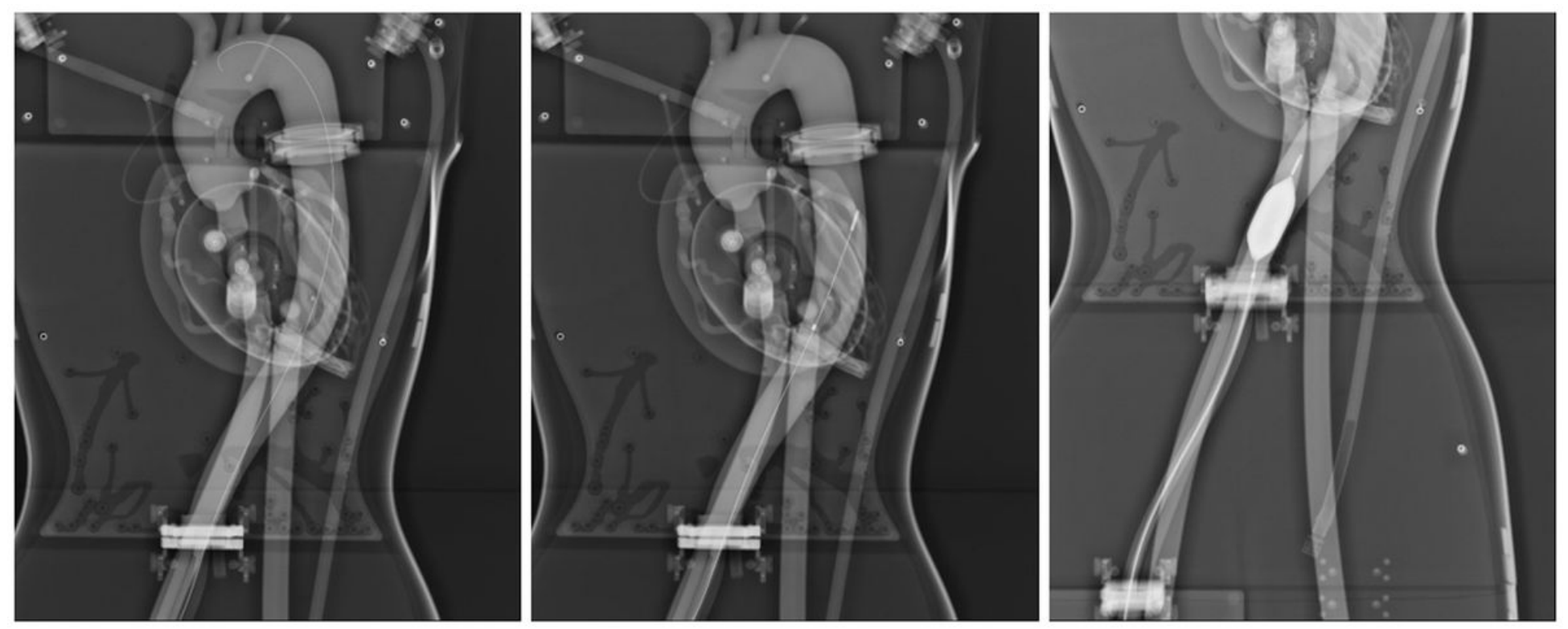

Figure 3 
X-ray of EVETM showing REBOA catheter X-ray was taken during the balloon manipulation to check the position of a guidewire and a balloon before inflation. A. Guidewire in the aorta of EVETM B. REBOA catheter before inflation C. REBOA balloon in the aorta of EVETM

Residents ( $n=16)$

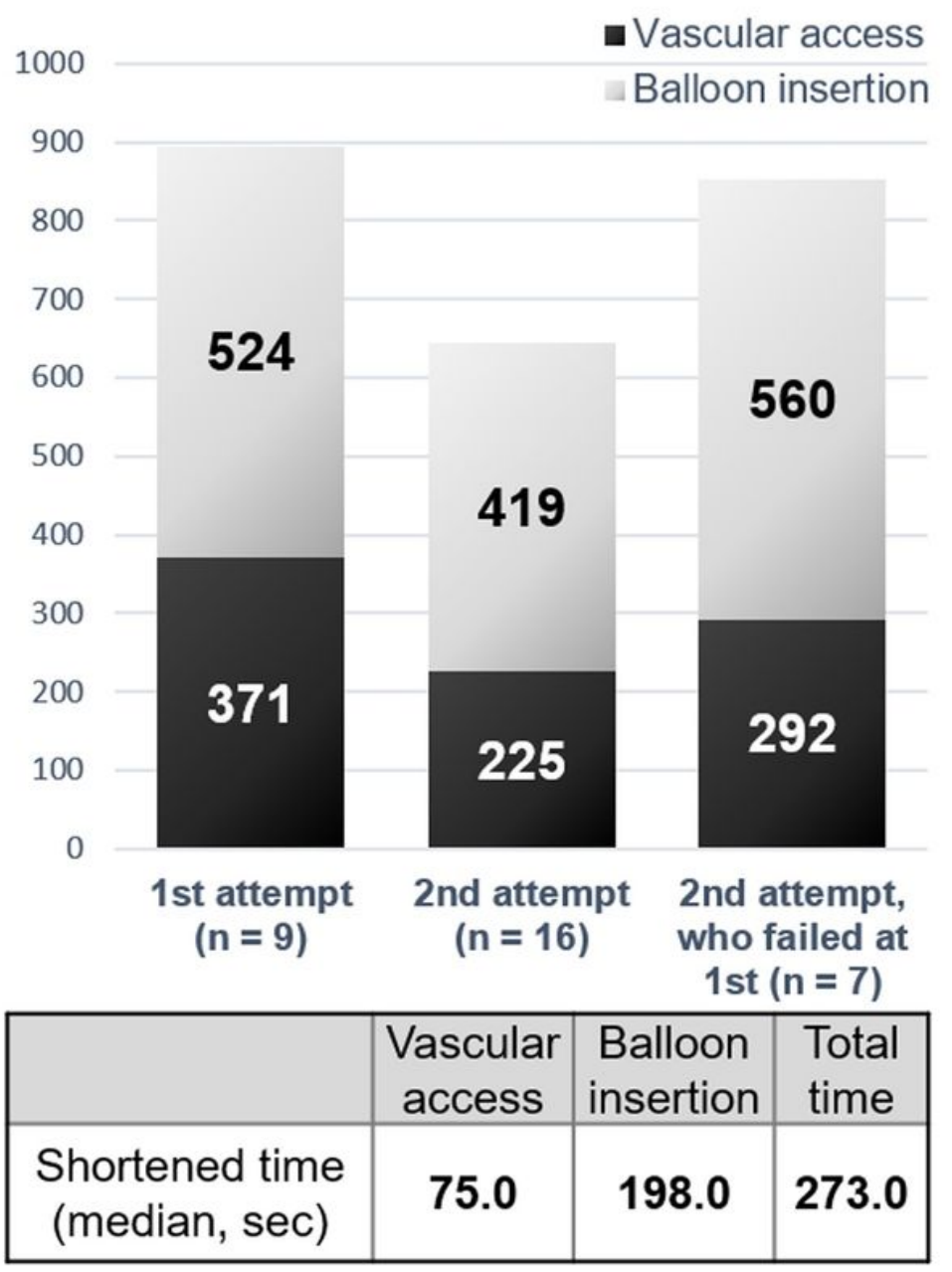

Specialists $(n=12)$

1000

- Vascular access

Balloon insertion

900

800

700

600

500

400

300

200

100

0

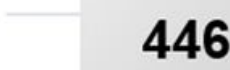

446

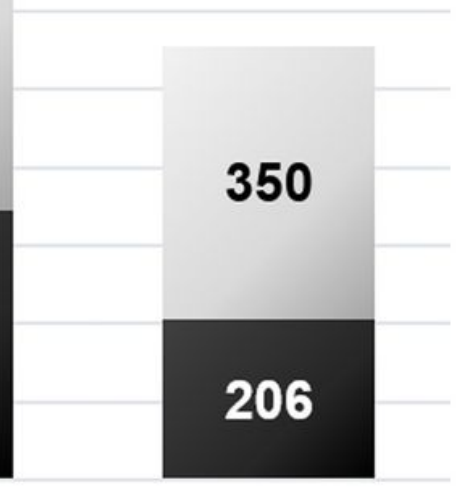

1st attempt

2nd attempt

\begin{tabular}{|c|c|c|c|}
\hline & $\begin{array}{c}\text { Vascular } \\
\text { access }\end{array}$ & $\begin{array}{c}\text { Balloon } \\
\text { insertion }\end{array}$ & $\begin{array}{c}\text { Total } \\
\text { time }\end{array}$ \\
\hline $\begin{array}{c}\text { Shortened time } \\
\text { (median, sec) }\end{array}$ & $\mathbf{1 1 6 . 0}$ & $\mathbf{9 7 . 0}$ & $\mathbf{2 8 9 . 5}$ \\
\hline
\end{tabular}

Figure 4

Changes in time for procedure The median time for vascular access and balloon insertion was markedly shortened at the second attempt compared to the first attempt both in residents and specialist groups. 

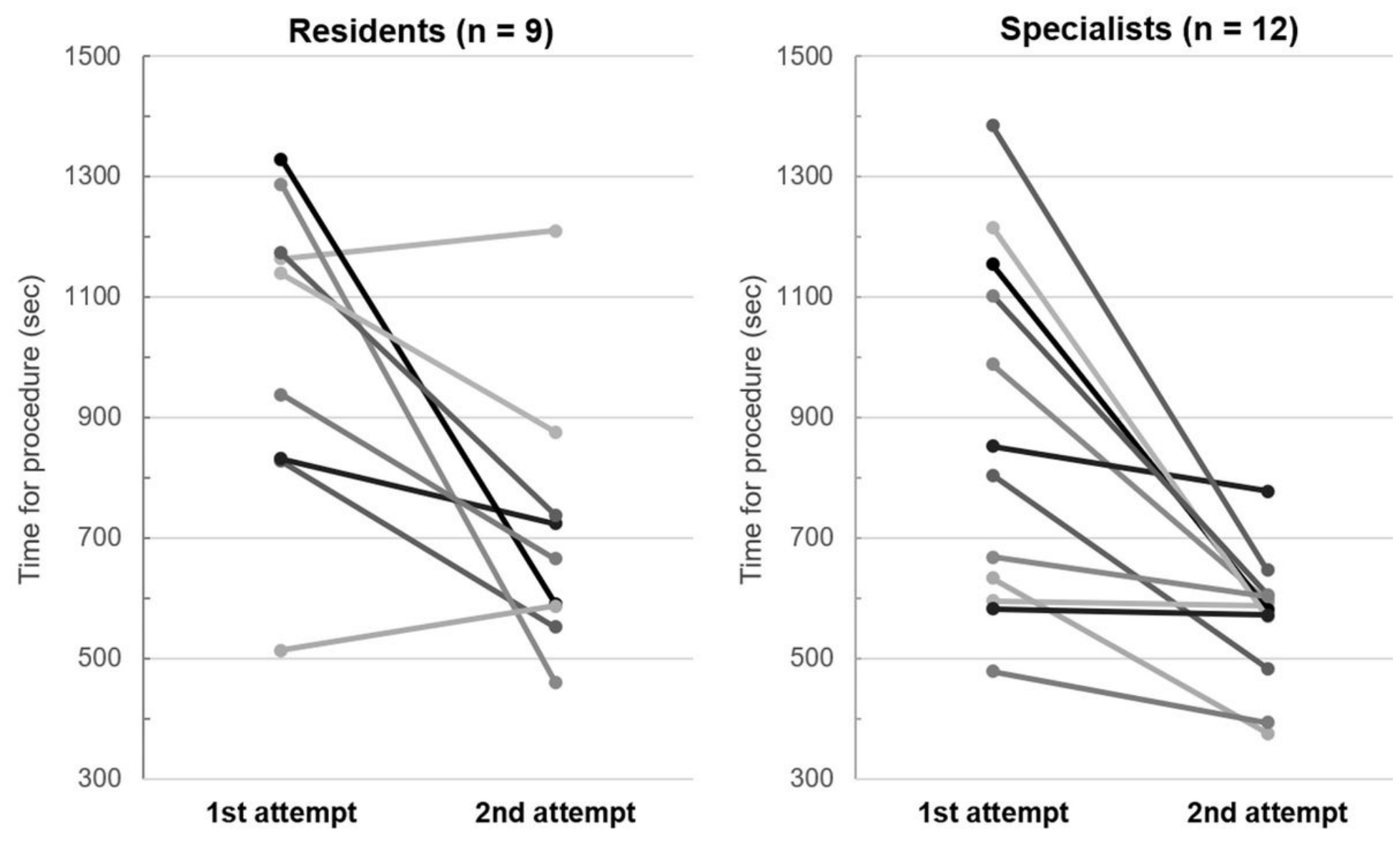

Figure 5

Line plots of time for procedure Each participant showed dramatic decrease from first to second attempt except one participant from the resident group. 